GLOBAL MEDICAL ETHICS

\title{
Blinkered objections to bioethics: a response to Benatar
}

\section{J Taylor}

In a recent commentary, S R Benatar criticised the debates over organ donation and kidney selling for being located within a "narrow and inadequate framework". Benatar levels four charges against those who engage in the current organs debate: that they myopically focus on saving lives; that they accept the dominance of market orientated approaches to health care; that they reify individualism, and that they engage in limited moral arguments. Given the importance of the organs debate it is imperative that the misunderstandings of it on which Benatar's criticisms are based are dispelled. Accordingly, I will consider and reject each of his objections in turn.

$\mathrm{n}$ a recent commentary, S R Benatar criticised the debates over organ donation and kidney selling for being located within a "narrow and inadequate framework". ${ }^{1}$ (For the sake of brevity I will refer to these issues as "the organs debates".) Benatar levels four charges against those who engage in the current organs debate. Given the importance of the organs debate it is imperative that the misunderstandings of it on which Benatar's criticisms are based are dispelled. Accordingly, I will consider and reject each of his objections in turn.

\section{A MYOPIC CONCERN FOR SAVING LIVES?}

Benatar's first charge is that the emphasis that the participants in the organs debate place on saving lives is "myopic". Benatar states that it is "striking and of concern that there is no mention in all of these debates in most bioethics journals of the many millions of people dying... because of lack of food or access to even the most basic health care". This claim is compatible with some journals publishing some articles on organ markets that do address this concern-as indeed they do. ${ }^{23}$ Benatar's concern is thus not that the participants in the organs debates ignore the issue of the premature deaths of "many millions" of persons, but that they do not address it as fully as he would like. The first response to this charge is to note that unless Benatar can show that the issue of how to prevent the premature deaths of the "many millions" is directly related to the organs debates, then the participants in the latter debate are perfectly justified in failing to address the separate debate over how to prevent death by causes other than kidney failure. Perhaps, however, Benatar is lamenting the fact that effort is being expended on debating the morality of kidney sales when it could be spent on addressing the question of how to avoid the "many millions" of premature deaths. If so, then for Benatar's objection here to be sound it must be the case that the more effort that is spent by physicians and bioethicists on addressing this latter question then the more likely it is that the deaths in question will be prevented. As Benatar notes, however, it is not clear that "physicians and bioethicists could have any influence in preventing these premature deaths". Given this, it is not clear that encouraging the participants in the organs debate to discuss the issue of death by starvation or deaths that occur because of a lack of access to health care would achieve anything at all-apart from diminishing our understanding of the issues of the organs debates.

\section{MARKET DOMINANCE?}

Benatar's second objection is that: "The language in which discussions about organ donation takes place is the language of the market," and that it "has become almost uncontested that market forces and money are the dominant forces governing health care provision". There are three responses to this charge. First, it is false that "the language in which discussions about organ donation takes place is the language of the market". One of the most widespread objections to kidney selling is that such a practice would lead to the commodification of human kidneys. Accordingly, the proponents of this objection allege kidney markets should be prohibited because there are areas of human life to which the language of the market should not apply. ${ }^{4}$ Second, it is also false that it "has become almost uncontested that market forces and money are the dominant forces governing health care provision". As Radcliffe Richards notes at the start of her often cited article in which she responds to the charge that kidney sales are immoral, it is agreed by almost all that such sales are wrong. ${ }^{6}$ Rather than going uncontested, then, the view that the market should be the primary provider of health care, and so markets for kidneys should be allowed, is the minority position. Moreover, the condemnation of kidney selling is not confined to persons who write journal articles on this subject, for most countries now explicitly ban commerce in human kidneys for transplant. Third, even persons who hold that kidney sales are morally permissible do not necessarily believe that money is or should be the dominant force governing health care provision. Many hold that although persons should be allowed to sell their kidneys, they should only be allowed to sell them to a single purchaser who will then distribute the procured kidneys-for example, on the basis of medical necessity. ${ }^{7}$

\section{REIFIED INDIVIDUALISM?}

Benatar's third charge is that the current organs debates take place "within a moral culture that reifies individualism", and that it is desirable to promote a "more generous moral culture". Although both Benatar's descriptive claim and his normative claim might be true, neither can be used to criticise how the current organs debates are conducted. First, to criticise the moral climate in which a debate takes place is not to criticise the debate itself. Second, many of the participants in this debate do discuss ways of encouraging such donation. ${ }^{8}$ Indeed, one of the primary arguments marshalled against the moral legitimacy of kidney selling is that it would discourage donation. ${ }^{9}$

\section{LIMITED MORAL ARGUMENTS?}

Benatar's final charge is that "when arguing about the ethics of organ donation it seems that only the moral theories of right and wrong action (deontology) or of balancing 
outcomes (utility) are debated". He claims that this focus indicates the theoretical impoverishment of the organs debates, for its participants accordingly fail to refer to the duty of non-maleficence, virtue theory, the idea of a duty to care for all patients, and the fiduciary nature of the doctor/ patient relationship. Unfortunately, there are several philosophical mistakes than undermine Benatar's claim that the debate over organ donation and kidney selling currently utilises only limited moral arguments. First, Benatar characterises deontology as the only ethical theory that is concerned with right and wrong actions. This is false. Both deontologists and utilitarians are concerned with the question of what makes an action right or wrong. Second, both deontologist and utilitarian participants in the organs debates could (and often do) address the issues of nonmaleficence, the idea of a duty to care for all patients, and the fiduciary nature of the doctor/patient relationship. A deontologist, for example, would be concerned with whether the removal of a kidney from a healthy person violates any moral duty to avoid harm, irrespective of the benefits that such harm might generate. A utilitarian would take the possible harm of the removal of a kidney into account when deciding whether the greatest good could be brought about by this act. Deontologists and utilitarians debate about whether physicians have a duty to care for all of their patients, irrespective of the benefits of such care. Similarly, many deontologists take seriously the fiduciary nature of the physician/patient relationship for its own sake, whereas utilitarians would only take it seriously if doing so would promote overall happiness. Third, although Benatar is correct that "considerations arising from virtue theory" are largely absent from the debate over organ donation and kidney selling he overlooks the reason for this. Virtue theory is primarily concerned with addressing the question of how a good person should live. As such, it is ill suited to address the moral dimension of public policy, which is concerned with specific issues, such as which acts should be prohibited-for example, kidney selling-or encouraged-for example, organ donation.

\section{CONCLUSIONS}

Benatar claims that the current organs debate emerges from a "blinkered mindset", and that rather than focusing on the "health of individuals" bioethicists should instead be concerned with "the lives of millions" and "should be working tirelessly to promote global solidarity". However, none of his four charges are sound. Moreover, Benatar should realise that to be concerned with "the lives of millions" requires one to be concerned with the lives of individuals, for the millions that he is concerned with simply are an aggregate of individuals. These concerns are thus not exclusive.

Correspondence to: J S Taylor, Department of Philosophy, Lovisiana State University, Baton Rouge, LA 70803, USA; jtayl25@|su.edu

Received 14 August 2004

Accepted for publication 6 September 2004

\section{REFERENCES}

1 Benatar SR. Blinkered bioethics. J Med Ethics 2004;30:291-2.

2 Zutlevics TL. Markets and the needy: organ sales or aid? J Appl Philos $2001 ; 18: 297-302$

3 Taylor JS. Stakes and kidneys: why markets in human body parts are morally imperative. Aldershot, UK: Ashgate, 2005: ch 9.

4 Brecher B. Buying human kidneys: autonomy, commodity, and power. J Med Ethics 1991;17:99.

5 Radin MJ. Market inalienability. Harv Law Rev 1987;100:1849-937

6 Radcliffe Richards J. Nepharious goings on: kidney sales and moral arguments. J Med Philos 1996;21:375-416.

7 Erin CA, Harris, J. An ethical market in human organs. J Med Ethics 2003;29:137-8.

8 Archard D. Selling yourself: Titmuss's argument against a market in blood. J Ethics 2002;6:87-103.

9 Abouna GM, Sabawi MM, Kumar MSA, et al. The negative impact of paid organ donation. In: Land W, Dossetor JB, eds. Organ replacement therapy: ethics, justice, commerce. New York, NY: Springer-Verlag, 1991:164-72.

\section{A response to J S Taylor}

\section{S R Benatar}

c m very pleased to see the response by J S Taylor to my critique of the "organs debate". He makes some notable and important points, but also some errors to which attention should be drawn.

Taylor erroneously attributes to me concern that the organ debate excessively focuses on saving the lives of a few people. My concern was about the narrow framework within which the debate is embedded and that it focuses on the lives of a few privileged people-those who can pay-while largely neglecting the lives of those who cannot. The fact that some attention has been paid to such issues in some journals does not negate the importance of my claim. Moreover, it is not that the question of millions of premature deaths has not been addressed as fully as I would like, as Taylor claims, but rather that it has not been addressed as fully as required by the magnitude of the problem. ${ }^{1}$ There is more than a subtle distinction between what I wrote and Taylor's interpretation of this. The organs debate may indeed justifiably be seen as separate, but his fear that taking on the broader debate may diminish "our understanding of issues in the organs debate" is unconvincing.

Taylor claims that my heightened concern for the "lives of millions" leads me to overlook that these millions are "simply" (my italics) an "aggregate of individuals". As a physician who has personally delivered health care to thousands of individuals over almost four decades, and who has been privileged to receive good care, I am well aware of the importance of caring for individuals. I am, however, also deeply aware that population health is not simply an extension of the health of individuals. ${ }^{2}$ Taylor may be correct that this could be the case if everyone had reasonable access to basic health care, but he is certainly not correct when access to health care is a privilege to which only some have access. The falsity of his claim is plainly evident in the USA. There, despite spending $50 \%$ of annual global health expenditure on $5 \%$ of the world's population (more than 
$\$ 5000$ per person on health annually-about twice that spent in any other nation in the world), millions of Americans lack access to health care. ${ }^{3}$ Moreover, the level of population health achieved in the USA is well below that achieved in many other countries. ${ }^{4}$ The incredulity of his claim is even more evident at the level of global health-where the wide and widening disparities in access to health care arguably constitute one of the major challenges to human life and security everywhere. ${ }^{5}$

It is undisputed that the purpose of medical practice and research is becoming increasingly influenced by market forces and market language. It is notable-for example, that of about $\$ 70$ billion spent annually on medical research $90 \%$ is devoted to those diseases that account for $10 \%$ of the global burden of disease. The pharmaceutical industry has a major influence on medical practice and research, which is why of 1393 new drugs marketed from 1975 to 1999 only 16 were for tropical diseases or tuberculosis. ${ }^{6}$ It seems that the purpose of medicine and medical research has been hijacked to serve the health and economic interests and the scientific curiosity of the most privileged!

The essence of my concern is that bioethics is in danger of being coopted into this agenda as exemplified by, although not limited to, the organs debate, with its excessive focus on the individual choices of those who can pay. The disagreements between Taylor and me are less important than the recent pleasing upsurge in interest in public health and public health ethics, which offers a broader moral perspective within which bioethics debates could contribute a more visionary approach to health and to saving lives. ${ }^{8-10}$

Correspondence to: Professor S Benatar, Department of Medicine, UCT, Observatory, Cape Town 7925, South Africa; sbenatar@uctgsh1.uct.ac.za

Received 9 September 2004

Accepted for publication 17 September 2004

\section{REFERENCES}

1 Pogge T. World poverty and human rights. Cambridge UK: Polity Press, 2002.

2 Kawachi I, Kennedy BP. The health of nations: why inequality is harmful to your health. New York: New Press, 2002.

3 Bloom BR. The future of public health. Nature 1999;402(suppl):63-4CS.

4 World Health Organization. Health systems: improving performance. Geneva: World Health Organization, 2000.

5 Benatar SR. The coming catastrophe in international health: an analogy with lung cancer. International Journal (Canadian Institute of International Affairs) 2001;56:611-31.

6 Trouiller P, Olliaro P, Torreele E, et al. Drug development for neglected diseases: a deficient market and a public health failure. Lancet 2002;359:2188-94.

7 Relman AR. Profit and commercialism in health care financing. In: Reich WE, ed. Encyclopedia of bioethics [2nd ed]. London: Simon \& Schuster, 1995:1063-6.

8 Buchanan D. An ethics for health promotion. New York: Oxford University Press, 2001.

9 Gostin LO, ed. Public health law and ethics: a reader. Berkeley: University of California Press, 2002.

10 Thompson A, Robertson A, Upshur R. Public health ethics: towards a research agenda. Acta Bioethica 2003;9:157-64. 